\title{
Mini review on euthanasia
}

\section{Introduction}

${ }^{1 '}$ This life in us however low it flickers or fiercely burns, is still a divine flame which ${ }^{2}$ no man dare presume to put out, be his motives never so humane and enlightened. To suppose otherwise is to countenance a death-wish. Either life is always or in all circumstances sacred, or intrinsically of no account; it is inconceivable that it should be in some cases the one, and in some the other'. Malcolm Muggeridge.

'Euthanasia is one of society's most widely and fiercely debated moral issues. No one is able to determine the significance of one's life and the quality a person should live. Euthanasia is categorized into two separate definitions; active and passive euthanasia. Euthanasia gives the terminally ill the ability to orchestrate their death. Euthanasia lifts a burden from the sufferer as well as their caretakers. Euthanasia gives the terminally ill the final dignifying say which allows them to practice the ultimate freedom; the right to die.

The word "euthanasia" comes from the Greek -- "eu" meaning "goodly or well", "thanatos" means "death." So, euthanasia is literally the "good death.

Euthanasia is split into two different categories; active and passive euthanasia.

\footnotetext{
${ }^{1}$ www.quotes of Malcolm Muggeridge.com

${ }^{2}$ www.bioethics.flthsbiosci.org
}

\section{Active euthanasia}

The active acceleration of a "good" death by use of drugs etc, whether by oneself or with the aid of a doctor.

\section{Passive euthanasia}

Passive euthanasia occurs when the patient dies because the medical professionals either don't do something necessary to keep the patient alive, or when they stop doing something that is keeping the patient alive. as

a. Switch off life-support machines

b. Disconnect a feeding tube

c. Don't carry out a life-extending operation

d. Don't give life-extending drugs

\section{Moral difference between killing and letting die}

Many people make a moral distinction between active and passive euthanasia. "3"They think that it is acceptable to withhold treatment and allow a patient to die, but that it is never acceptable to kill a patient by a deliberate act."

${ }^{4}$ "Some medical people like this idea'. They think it allows them to provide a patient with the death they want without having to deal with the difficult moral problems they would face if they deliberately killed that person.

\author{
Volume 7 Issue 6 - 2017
}

\author{
Marriam Gul Thaheem \\ Department of Oncology, Jinnah Postgraduate Medical Center, \\ Pakistan
}

Correspondence: Marriam Gul Thaheem, Department of Oncology, Jinnah Postgraduate Medical Center, Pakistan, Email marrygul@hotmail.com

Received: February 16, 2017 | Published: April 17, 2017

${ }^{5}$ The issue of Euthanasia is itself highly controversial, and has become an increasingly contentious issue in contemporary society.

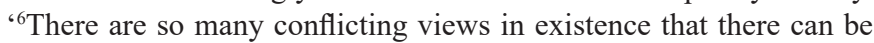
no ultimate right or wrong answer'.

'In this essay I will be looking at the differing opinions of those for and against, but will also offer my own thoughts and understanding of the difficult subject'.

7"Euthanasia is often referred to in the media as Mercy killing, this is the term given to the intentional termination of the life of one human being by another". ${ }^{86}$ However, euthanasia can then be split into categories of active, passive, voluntary and involuntary'. ' 'Voluntary euthanasia is essentially assisted suicide, where the patient asks a doctor to help them die'. ${ }^{10}$ " Non-voluntary euthanasia is along the same lines as voluntary euthanasia, however in this case the patient cannot be asked for consent'. For example if treatment was withdrawn from a patient in a deep coma, or persistent vegetative state, but for their own benefit. ${ }^{11}$ 'Involuntary euthanasia on the other hand occurs in the circumstance where the patient is killed "supposedly" for their sake, but without having given their consent'.

${ }^{12}$ 'Euthanasia is a long, smooth-sounding word, and it conceals its danger as long, smooth words do, but the danger is there, nevertheless'. Pearl S Buck.

\footnotetext{
${ }^{3}$ www.deadpanthoughts.com

${ }^{4}$ www.bbc.co.uk

${ }^{5}$ Hotessays.blogspot.com

${ }^{6}$ Hotessays.blogspot.com

7 ibid

8 ibid

9 ibid
} 
${ }^{10} \mathrm{ibid}$

${ }^{11}$ ibid

${ }^{12}$ www.finestquotes.com

\section{Arguments for euthanasia}

a. It provides a way to relieve extreme pain

b. It provides a way of relief when a person's quality of life is low

c. Frees up medical funds to help other people

d. It is another case of freedom of choice

The good death. ${ }^{13}$ According to this view, certain ways of dying are better than others'. ${ }^{14}$ “Usually a good death is described ideally as drifting into death in a pleasing environment as one falls asleep'. ${ }^{15}$ "The ancient Roman orator and statesman Cicero said that a good death is the ideal way of respecting natural law and public order by departing from the earth with dignity and tranquility'.16", Euthanasia can be seen as a way to assure that a person dies in a dignified and appropriate manner'.

${ }^{17}$ 'Right to maintain human dignity'. ${ }^{18}$ " This argument is similar to the concept of the good death, except that the objective is to avoid a poor quality of life during the dying process rather than seek out a particular idealized way of dying the good death". ${ }^{19}$ "There are great individual differences in what constitutes a dignified way to live and die'. ${ }^{20}$ 'Commonly mentioned indignities to justify premature death include: being a burden to others, living a deteriorated state incapable of normal daily activities, having to be placed in a hospital or a nursing home, and being dependent upon intrusive medical apparatus to continue living or engaging in everyday tasks". ${ }^{21}$ "The general public often assumes that certain chronic and terminal illnesses inevitably result in a poor quality of life". ${ }^{22}$ "However, research suggests that the psychosocial environment determines quality of life as much or more than the nature of the illnesses.

23 "Even if one disagrees with any form of eugenics program for economic reasons, one may still consider the fact that social pressure often exists in situations where medical resources are limited'. ${ }^{24}$ 'The concept of distributive justice involves looking at the collective good or general welfare as something to' be shared among the total membership of society". ${ }^{25}$ "When resources are limited, society may question, for example, if it is worth expending tremendous resources to maintain the life of one incurably ill individual in a vegetative unconscious state rather than using those resources to help cure those who have promising prognoses for recovery'.

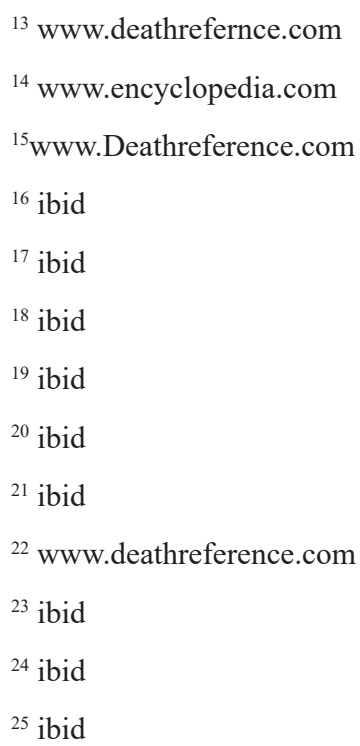

\section{Funding}

None.

\section{Acknowledgements}

None.

\section{Conflicts of interests}

The authors declare that there is no conflict of interest. 